\title{
1483-1546: Lutero et/aut Vitoria 1483-1546: Luther et/aut Vitoria
}

\section{Simona Langella}

Università di Genova

ITALIA

Simona.Langella@unige.it

[Hipogrifo, (issn: 2328-1308), 7.2, 2019, pp. 445-459]

Recibido: 01-04-2019/ Aceptado: 03-05-2019

DOI: http://dx.doi.org/10.13035/H.2019.07.02.35

Resumen. La intención de nuestro trabajo, aunque en el espacio limitado de unas pocas páginas, es mostrar cómo algunas categorías esenciales del pensamiento de la modernidad se desarrollaron con respecto a algunos temas fundamentales - como el uso de la razón en la esfera teológica, el valor de la ley, la naturaleza del poder eclesiástico y político, la legitimidad de la guerra, el dominio-, a partir de la refutación de la interpretación de Martin Lutero por parte de Francisco de Vitoria y cómo este último contribuyó decisivamente al nacimiento del pensamiento moderno.

Palabras clave. Reforma; segunda escolástica; pensamiento moderno; razón; ley; poder eclesiástico y político; guerra; dominium.

Abstract. The intention of our work, although in the limited space of a few pages, is to show how some essential categories of modernity thinking developed with respect to some fundamental issues, - such as the use of reason in the theological sphere, the value of the law, the nature of ecclesiastical and political power, the legitimacy of war, dominium-, based on the refutation of Luther's interpretation by Francisco de Vitoria and how the latter contributed decisively to the birth of modern thought.

Keywords. Reform; Second scholastic; Modern thinking; Reason; Law; Ecclesiastical and political power; War, Dominium. 


\section{INTRODUCCIÓN}

Extraño destino el de Martín Lutero y de Francisco de Vitoria: los dos nacieron y murieron el mismo año ${ }^{7}$. El primero llevó a una transformación de la Iglesia por medio de unas consecuencias funestas para su unidad; el segundo, Maestro de Prima Theologiae de la Universidad de Salamanca, renovó el método de enseñanza de la ciencia teológica centrándolo en la Summa Theologiae de Tomás de Aquino. Uno será el representante máximo de la Reforma, el otro el fundador de la Escuela de Salamanca y propulsor del renacimiento de la Escolástica española del siglo XVI. Los dos, sin embargo, aunque por diferentes caminos, aspiraron a una innovación de la Iglesia. En efecto, los dos veían que se necesitaba un cambio profundo de las instituciones eclesiásticas, pero actuaron por medio de modos y medios muy diferentes. Esta necesidad reformadora, fue lo que impulsó a Vitoria en su relectio De potestate papae et concilii de 1534 a plantearse la cuestión de cuáles fueron las medidas restrictivas más eficaces para limitar los casos de abuso de la potestad papal ${ }^{2}$. Su interés por la reforma de la Iglesia no es, sin embargo, el de los teólogos conciliaristas, como Jacques Alain o John Mair ${ }^{3}$, de la Universidad de París, donde Vitoria consiguió el título de doctor en Sagrada Teología 4 . De hecho, la exigencia de reforma que Vitoria advirtió no afectará nunca a la convicción de la potestad suprema del pontífice, aunque algunos puntos de su doctrina, como por ejemplo aquel en el que propone una cierta resistencia a los abusos de la curia romana, influirán en cierto espíritu de independencia que caracterizará precisamente a la actitud de los teólogos españoles durante el concilio de Trento5. Por una parte, Vitoria insistía en la afirmación de un pleno reconocimiento de los poderes del concilio si está legítimamente reunido, pues para Vitoria las decisiones de los concilios constituyen una de las fuentes principales a las que el teólogo debe referirse, porque gracias a ellas la Iglesia determina la definitiva interpretación de la verdad revelada6; por la otra, nunca planteó el discutir la superioridad de la potestad papal respecto al concilio, aunque, como ya está mencionado, se formó en el centro propulsor del conciliarismo del siglo $\mathrm{XV}^{7}$. Pero los puntos de confrontación entre Lutero y Vitoria no terminan aquí como veremos.

\footnotetext{
1. Ramón Hernández señala que la fecha correcta de nacimiento de Francisco de Vitoria es 1483. Ver Hernández Martín, 1995, pp. 11-16.

2. Ver Vitoria, Relecciones jurídicas y teológicas, vol. I, pp. 756-861.

3. Ver Langella, 2017a, vol. I, pp. 729-736.

4. Ver Langella, 2011, p. 5.

5. Ver Urdánoz, 1960, p. 412

6. En su comentario a la I pars de la Summa Theologiae, Vitoria subraya la importancia de las decisiones conciliares en materia de la fe. En particular, explicando el artículo 8 de la I quaestio Vitoria pone en claro que el teólogo debe conocer esta decisión para poder argumentar de modo conveniente e las disputas teológicas. Ver Langella, 2013, pp. 83-86 y Apéndice VI, pp. 408-411.

7. Recuérdese que Pierre d'Ailly y Jean Gerson, los mayores exponentes de las teorías conciliaristas durante el siglo $\mathrm{xV}$, fueron también promotores de la exigencia de una reforma radical de la Iglesia in capite et in membris. Ver Urdánoz, 1960, p. 411. Y asimismo Juan de Jesús María, 1947, pp. 104 y 106.
} 


\section{RAZÓN Y CIENCIA TEOLÓGICA}

Analizando la carrera académica de Vitoria, titular de la cátedra de Prima Theologiae del Alma Mater española casi durante veinte años, es imposible no ver en su reflexión intelectual y en sus decisiones académicas la voluntad de constituir un contrapunto a las instancias de la Reforma luterana y a su evolución ${ }^{8}$. Para aclarar es bueno recordar que, además de reforzar el valor de la ciencia teológica ${ }^{9}$ desde un punto de vista epistemológico ${ }^{10}$, y no solo práctico, contra las críticas usadas por Lutero ${ }^{11}$ al uso de la ratio ${ }^{12} \mathrm{y}$, en particular, al uso de la filosofía aristotélica ${ }^{13}$ en

8. En el espacio de este trabajo no se podrá n tratar todos los puntos de coincidencia y deferencia por lo que respecta al pensamiento de esos dos pensadores. Enviamos a otro sitio la discusión sobre algunas cuestiones estrictamente teológicas, como la cuestión de las indulgencias o la existencia del purgatorio. Sobre estos dos últimos problemas Vitoria expresa claramente su condena acerca de la postura que adopta Lutero en su comentario a la Summa theologia. Ver Langella, 2013, Apéndice IV, pp. 160 y 174. 9. Vitoria comentó la I quaestio de la I pars de la Summa Theologiae más de dos veces, es decir, durante dos distintos ciclos de lecciones, las habidas en 1531-1533 y las de 1539-1541. Ver Langella, 2013, Apéndice IV, pp. 154-255, Apéndice V, pp. 262-371, Apéndice VI, pp. 376-415. Ver también Langella, 2018, pp. 38-48.

10. Para Vitoria la teología goza del estatuto de ciencia pues sus procedimientos cognoscitivos, cuando están fundadas sobre proposiciones absolutamente verdaderas y ciertas, remiten en las conclusiones a un estatuto de verdad indudable. En otros términos, para Vitoria, la teología es ciencia revelada o de autoridad. No argumenta para demostrar sus principios, aunque a partir de ellos pueda argüir para demostrar otras verdades o discutir con quienes admiten los principios revelados. Así afirma comentando el artículo octavo, q. 1 de la primera pars de la Summa Theologiae: «Prima conclusio: theologia non arguit ad probandum sua principia, sed tantum probat conclusiones ex principiis. Secunda conclusio: disputat tamen arguendo contra negantes eius principia. Tertia conclusio: disputat etiam salvando argumenta facta contra eius principia» (Langella, 2013, Apéndice VI, pp. 408-409).

11. Tanto en su Disputatio contra scholasticam theologiam (1517), come en la Disputatio Heidelbergae habita (1518), Lutero critica ásperamente la filosofía aristotélica y el uso de la ratio en el estudio de la ciencia teológica. En la primera de estas dos Disputationes - convencido de que solo la fe salva- sostiene: «43. Error est dicere: sine Aristotele non fit theologus. Contra dictum commune. 44. Immo theologus non fit nisi id fiat sine Aristotele. 45. Theologus non logicus est monstrosus haereticus. Est monstrosa et haeretica oratio» (Luther, Disputatio contra scholasticam theologiam, WA, 1, p. 226). Y añade: «47. Nulla forma syllogistica tenet in terminis divinis [...]. 49. Si forma syllogistica tenet in divinis, articulus Trinitatis erit scitus et non creditus. 50. Breviter. Totus Aristoteles ad theologiam est tenebrae ad lucem [...]. 52. Bonum erat Ecclesiae, si theologis natus non fuisset Porphirius cum suis universalibus» (Luther, Disputatio contra scholasticam theologiam, WA, 1, p. 226). Y también en sus cuarenta tesis heidelbergenses advierte: «Qui sine periculo volet in Aristotele philosophari, necesse est ut ante bene stultificetur in Christo». Luther, Disputatio Heidelbergae habita, WA, 1, p. 355.

12. Para Vitoria, la razón es en sentido amplio revelación y, por tanto, en cuanto don divino, no debe ser garantizada ni mucho menos negada como hacen los herejes. Claramente no se trata, por lo respecta a la teología, de probar la fe con la razón, sino de demostrar que las verdades de fe están en armonía con ella. «Est notandum quod nullum est inconveniens afferre cum auctoritatibus rationes naturales, nam et ipsum lumen naturale est donum Dei et revelatio largo modo accepta [...] et certe videtur genus ingratitudinis dicentium quod non est utendum rationibus, ut dicunt haeretici» (Langella, 2013, Apéndice IV, p. 248).

13. Vitoria da importancia a la razón natural y a la filosofía en el campo teológico hasta tal punto que para él sostener que la razón es demoniaca es una afirmación herética: «Et impium et haereticum est dicere, ut isti novi dicunt haeretici, quod daemoniacum est opus rationibus naturalibus et philosophorum uti in theologia, quia Dei donum est lumen naturale, ut patet ex illo psalmi 4, [7]: "Signatum est super nos 
el estudio de la teología ${ }^{14}$, Vitoria trabaja también en el ámbito de la filosofía moral un profundo "renacimiento" del derecho natural a través de una reflexión centrada esencialmente en el concepto de lex ${ }^{15}$.

\section{EL DERECHO Y LA LEY}

El desarrollo del tema de la ley como punto cardinal para la reflexión ética, y para establecer los límites mismos del poder político y eclesiástico ${ }^{16}$, es también una respuesta evidente al sola gratia ${ }^{17}$ de Lutero ${ }^{18}$, que ya en la Disputatio contra scholasticam theologiam ${ }^{19}$ de 1517 a este propósito afirmaba: «Omne opus legis sine gratia Dei foris apparet bonum, sed intus est peccatum» ${ }^{20}$. Para comprender este punto tan delicado de la reflexión de Lutero hay que tener presente que él distingue el orden exterior, o sea, el de la relación con los demás, en el que la sola fe no es suficiente, del orden de la conciencia, en el que el cristiano es libre por su

lumen vultus tui, Domine". Et ad Romanos primo, [19], revelationem vocat rationem naturalem; a Deo ergo est naturalis ratio et non a daemone» (Langella, 2013, Apéndice V, p. 362). Nótese cómo Vitoria no define esa actitud solo como temeraria -así como afirma a propósito de la postura sostenida por quienes niegan la autoridad de los santos Doctores en el campo teológico- pero denuncia su carácter herético.

14. Lutero atribuye a los doctores scholastici errores tanto de contenido, como de método. Los primeros radican al haber optado por una solución pelagiana de en las relaciones entre méritos y gracia, mientras que los segundos consisten en haber exagerado la importancia de la lógica aristotélica, olvidando así respetar la correcta jerarquía de las autoridades ordenadas al discurso teológico. Ver Quinto, 2011, p. 214. 15. El comentario de Vitoria a la I-Ilae, qq. 90-108, será el comienzo de un nuevo filón ético-jurídico que caracterizará la reflexión, no solo española, de los siglos XVI y XVII. Ver Vitoria, De legibus, 2010.

16. Ver Langella, 2017b, pp. 45-61.

17. Sin embargo, sola Scriptura no significa, para Lutero, que haya que renunciar a todo criterio correctivo de la conducta humana, como las leyes o la autoridad seglar; más bien él establece la Escritura como criterio fundamental, límite insuperable tanto para la conducta individual, como para el legislador. Ver Contreras Aguirre, 2018, p. 168.

18. Con el principio de la "sola Scriptura "Lutero quiere expulsar de la teología no solo las autoridades eclesiásticas, sino también y, sobre todo, las humanas, en particular las propiamente filosóficas. Ver Mondin, 2002, p. 147. En efecto, como nota Eugenio Andreatta (1996, p. 287), su «strategia nei confronti di Aristotele è legata a un preciso progetto [...]. Nell'obiettivo delle sue critiche c'è la stessa forma mentis aristotélica, a suo giudizio incompatibile con il cristianesimo».

19. El texto tiene como título: Ad subscriptas conclusiones respondebit Magister Franciscus Guntherus Nordhusensis pro Biblia, Praesidente Reverendo patre Martino Luthero Augustiniano, Sacrae Theologiae Vuittenberg. Decano, loco et tempore statuendis. La Disputatio de 1517 consta de noventa y siete tesis sobre la base de las que se habría desarrollado una disputa bajo la presidencia del doctor Martín Lutero y el respondens era Franz Günther. Ellas representan la radical toma de distancia por parte de Lutero de la filosofía aristotélica y de la teología escolástica, pero también presentan temas clásicos del pensamiento de Lutero, como la incapacidad de la voluntad a desear algo bueno sin la gracia; la radical corrupción de la naturaleza a causa del pecado; la predestinación a prescindir de las obras; la esencial maldad de toda obra humana sin la gracia. Ver Quinto, 2011, pp. 210 y 211, nota 11.

20. Luther, Disputatio contra scholastica theologiam, WA, 1, p. 227. Y el año siguiente reafirma: «Lex Dei, saluberrima vitae doctrina, non potest hominem ad iusticiam promovere, sed magis obstet». Luther, Disputatio Heidelbergae habita, WA, 1, p. 353 
fe en el Evangelio ${ }^{21}$. Su postura debe entenderse a partir del hecho que, aun reconociendo el papel de la autoridad constituida y la obediencia debida a ella, Lutero determina en la conciencia de cada uno un límite infranqueable para el poder político ${ }^{22}$. El poder temporal puede promulgar, de hecho, solo leyes que se refieren a los cuerpos y a los bienes exteriores ${ }^{23}$. Pero por lo que respecta a las almas, solo Dios tiene el derecho de gobernarlas ${ }^{24}$. Para él, «In Ecclesia autem et fide Christi neque civiles leges nec divinae leges Mosi conscientiam ligant aut damnant. Extendi enim debent tantum super corpus et res externas. Ergo conscientiam liberatam per Christum coram Deo nec ledere nec iuvare debent. Et conscientia debet in Christo, qui super et extra omnes leges est, haerere et postea illas leges servare in officium caritatis extra conscientiam. Et haec est libertas Christiana» ${ }^{25}$. En consecuencia a la pregunta An ecclesia Dei sancta possit statuere aliquid observandum sub peccato mortali, que Lutero plantea en su obra De potestate leges ferendi in Ecclesiam de 1530, responderá: «Ecclesia nihil statuit, quod conscientiam coram Deo liget aut iustificet, sed conscientiam liberam relinquit, in sola gratia iustificandam, et sola fide servandam. Foris tamen constituit pro pace et concordia inter homines, ceu aliae civiles aut oeconomicae leges. Talia sunt summo honore amplectenda, quia non nocet fidei et prosunt paci»26.

Aquí, exactamente acerca de la cuestión de la obediencia en las relaciones de la autoridad seglar, la distancia con la especulación ético-jurídica de Vitoria se hace evidente ${ }^{27}$. Para el Maestro dominico la ley divina y la humana no difieren más que

21. En el orden exterior se necesita el poder coercitivo de las leyes. En el orden interior, por el contrario, Lutero «niega que las leyes humanas obliguen en el fuero de la conciencia, porque el fuero de la conciencia pertenece a Dios. Los hombres no pueden tomarlo para sí. Lutero explica que obligar en conciencia equivale a obligar bajo pena de condenación eterna. Como la legislación humana es temporal y no llega a lo eterno, habría una usurpación de potestades si el hombre mandase en el fuero de Dios» (Contreras Aguirre, 2018, p. 167)

22. «El cristiano sería libre por la fe, pero en cuanto a la carne siervo del pecado. Lutero establece la distinción entre la "consciencia in Evangelio" y "la caro in lege"» (López Hernández, 1981, p. 71). La distinción corresponde a la doctrina luterana de los dos órdenes: «el Reino de Cristo o ámbito espiritual invisible [...] y el Reino del mundo sometido al poder externo de la ley y de la espada» (López Hernández, 1981, p. 71)

23. Ver Luther, Von weltlicher Obrigkeit, wie weit man ihr Gehorsam schuldig sei, WA, 11, p. 262. A este propósito, fray Luis de León en su De legibus, q. 96, a. 3, sostiene, «contra Lutherum qui affirmavit nihil esse credendum nec precipiendum nisi quod expresso Dei verbo contineretur» (fray Luis de León, 2005, pp. 238-239), que la ley humana puede decretar algo que ni por ley natural, ni por ley divina nunca fue ordenado

24. «Lutero, negando la potestad legisladora de los hombres, reduce la tarea de los gobernantes a la reproducción de las normas morales y legales contenidas en las Escrituras, supuesto que nadie puede ordenar lo que Dios no ha querido ordenar» (Contreras Aguirre, 2018, p. 162).

25. Luther, In Isaiam Scholia ex D. M. Lutheri praelectionibus collecta 1532/7534, WA, 25, p. 322.

26. Luther, De potestate leges ferendi in Ecclesiam, WA, 30 II, p. 684.

27. Y no solo con Vitoria. En efecto, «los juristas y teólogos de Salamanca, cuando elaboran su teoría del derecho, tienen a Lutero como contradictor. Para los pensadores salmantinos, Lutero representa el quiebre con la tradición aristotélica y tomista del derecho, donde las normas de la ley positiva son consubstanciales a la naturaleza del hombre - de modo que aun en el estado de inocencia los hombres habrían necesitado leyes» (Contreras Aguirre, 2018, p. 160). 
para los autores, pues una depende solamente de Dios, la otra de Dios y de los hombres $^{28}$. Pero una obliga, así como la otra ${ }^{29}$. Una vez aclarado que no hay diferencia entre ellas con respecto a la obligatoriedad, Vitoria contesta directamente a la tesis de Lutero, para quien las leyes eclesiásticas no pueden obligar en conciencia bajo amenaza de pecado mortal, negación basada en el hecho, así como argumentaba ya Jean Gerson ${ }^{30}$, para quien ningún legislador humano nunca podría imponer una pena eterna que de hecho no puede ejecutarse ${ }^{31}$. Para Vitoria, que comparte sobre esta vexata quaestio la opinión general de los teólogos, las leyes humanas pueden ciertamente obligar por su fuerza bajo amenaza de pecado mortal: «leges humanae possunt obligare virtute sua ad mortale» ${ }^{32}$. Dicha fuerza obligante procede del indivisible nexo con la lex naturalis ${ }^{33}$. Lo cual no significa, sin embargo, que las leyes positivas sean únicamente copia de la ley natural, sino más bien que ellas no pueden ser contrarias a ella ${ }^{34}$.

\section{EN TORNO AL PODER POLÍTICO Y LA GUERRA}

Por otra parte, la misma concepción luterana según la cual la necesidad del poder político reside en la caída del hombre, a través de Adán, en el pecado y en la imposible redención de este último ${ }^{35}$, parece recordar, por contraposición, la concepción política de Vitoria, para quien el instinto de ser sociable, que mueve al hombre a formar la sociedad, sería, sin embargo, una inclinación natural ${ }^{36}$. La organización de la comunidad política para Vitoria está destinada a hacer que todos los hombres, a través de la ayuda recíproca con sus semejantes, cumplan la propia naturaleza: «Cum itaque humanae societates propter hunc finem institutae sint, ut scilicet alter alterius onera portaret, et inter omnes autem societates, civi-

28. La diferencia entre la ley divina y la humana reside en el hecho de que «lex divina intendit homines facere felices felicitate supernaturali, ita lex humana intendit facere homines felices felicitate humana et ad beatitudinem humanam illos perducere, sicut lex divina nititur eos ad beatitudinem aeternam ducere» (Vitoria, Comentarios a la Secunda secundae, vol. I, p. 192, q. 10, a. 8).

29. Ver Vitoria, De legibus, pp. 138-140 (q. 96, a. 4). Vitoria es explícito sobre la obligatoriedad de la ley humana tanto que llega a afirmar que: «Auctoritate autem legis nemo peccat, quia leges dant ius in foro conscientiae» (Vitoria, Relecciones jurídicas y teológicas, vol. II, p. 774).

30. El Canciller de la Universidad de París sostiene que las leyes humanas, tanto civiles como eclesiásticas, no pueden obligar de se bajo pena de pecado mortal, porque solo Dios: «potest dare praecepta affirmativa aut negativa sub poena mortis aeternae, quia illam infligere solus potest» (Ioannes Gerson, Liber de vita spirituali animae, lectio tertia, col. 38).

31. Ver Vitoria, De legibus, p. 140 (q. 96, a. 4).

32. Ver Vitoria, De legibus, p. 142 (q. 96, a. 4).

33. Ver Vitoria, De legibus, p. 134 (q. 96, a. 4).

34. Las leyes humanas no son un simple reflejo de la ley natural, aunque esta última sea el criterio de corrección de las leyes positivas. En efecto, el legislador humano tiene «una auténtica potestad creativa: su tarea legisladora no se limita a la copia de los mandatos divinos y naturales» (Contreras Aguirre, 2018, p. 162).

35. En efecto, si por un lado el cristiano es libre señor sobre todas las cosas y no sujeto a ninguna, por otra es asimismo siervo de todas las cosas y sujeto a cada una de ellas, ya que tiene precisamente una doble naturaleza, espiritual y corporal. Ver Luther, Tractatus de libertate christiana, WA, 7, p. 49. 36. Ver Vitoria, Relecciones jurídicas y teológicas, vol. I, p. 98. 
lis societas ea sit in quae commodius humanis necessitatibus subvenit, sequitur ergo civitatem esse (ut ita dixerim) naturalissimam communicationem naturaeque convenientissimam» ${ }^{37}$. Remitiéndose al Estagirita, Vitoria sostiene la innegable propensión natural de hombre a vivir en sociedad ${ }^{38}$ y, por tanto, afirmando la necesidad natural de la misma, admite igualmente la necesidad natural de los poderes públicos en cuanto indispensables a la realización de la comunidad ${ }^{39}$.

La recuperación por parte de Vitoria de la teoría de Tomás de Aquino de la guerra justa, discutida basándose en las normas del ius gentium, también parece una respuesta a las posturas de Lutero en relación de una posible guerra contra los turcos ${ }^{40}$. Más que una crítica al irenismo erasmiano ${ }^{41}$, del que, en la conclusión de su relectio De iure belli, si bien de forma tímida, recuerda los tonos de su pacifismo evangélico ${ }^{42}$, aquí, en el incipit de su relectio de junio de 1539, Vitoria condena, más bien, sobre el rastro de la bula Exsurge Domine de León X, de 1520, la opinión de Lutero, para quien, «si Turcae invadant christianitatem, illa est voluntas Dei, cui resistere non licet» ${ }^{43}$. Lutero, en efecto, argumentaba, ya desde 1518, que era inútil oponerse con las armas a los turcos, pues si Dios quería su victoria para castigar los pecados de los cristianos, a estos no les quedaba más que hacer penitencia, pues no era posible oponerse a la voluntad de Dios $^{44}$. Para Lutero era una equivocación intentar resolver con una guerra armada externa lo que requería más bien una batalla interna a los propios vicios ${ }^{45}$. Los turcos solo eran un instrumento en las manos de Dios, quien a través de ellos quería inducir a la conversión y penitencia a los cristianos y, por tanto, hubiera sido ciertamente impío luchar contra la acción di-

37. Vitoria, Relecciones jurídicas y teológicas, vol. I, p. 102.

38. Ver Vitoria, Relecciones jurídicas y teológicas, vol. I, p. 98.

39. «Patet ergo quod fons et origo civitatum rerumque publicarum non est inventum commentumve humanum, neque inter artificiata numerandum, sed tanquam a natura profectum, quae ad mortalium tutelam et conservationem hanc rationem mortalibus suggessit. Atque ex eodem capite consequitur eundem esse finem eandemque necessitatem publicarum potestatum. Si enim ad mortalium incolumitatatem necessaria sunt concilia coetusque hominum, societas autem nulla consistere potest sine vi aliqua et potestate gubernanti et providenti, idem omnino usus utilitasque publicae potestatis et societatis» (Vitoria, Relecciones jurídicas y teológicas, vol. I, pp. 102-104).

40. Ver Langella, 2009.

41. Sobre las relaciones entre Erasmo y Vitoria, ver Ramis Barcelò, 2018, pp. 95-99.

42. Los tonos casi erasmistas de las conclusiones finales de la relectio que invitan a la paz y a la moderación no vuelven a llevar la discusión sobre el tema de la guerra justa en el ámbito restringido de la virtud teologal de la caridad, sino que indican al lector el verdadero objetivo de la relectio: reiterar la absoluta necesidad de la paz. Ver Vitoria, Relecciones jurídicas y teológicas, vol. II, p. 848.

43. Vitoria, Relecciones jurídicas y teológicas, vol. II, p. 762. La afirmación fue condenada por la Iglesia con la bulla Exsurge Domine de León X, de 15 de junio de 1520: ver «Exsurge Domine», en Denzinger, 1996, n. 1484, p. 632. También Suárez considera esta afirmación contradictoria y ridícula. Ver Suárez, De triplici virtute theologicae, en Opera Omnia, vol. XII, 1857, p. 738.

44. Ver Luther, Resolutiones disputationum de indulgentiarum virtute, WA, 1, p. 535.

45. «Licet plurimi nunc et iidem magni in ecclesia nihil aliud somnient quam bella adversus Turcam, scilicet non contra iniquitates, sed contra virgam iniquitatis bellaturi deoque repugnaturi, qui per eam virgam sese visitare dicit iniquitates nostras, eo quod nos non visitamus eas» (Luther, Resolutiones disputationum de indulgentiarum virtute, WA, 1, p. 535). 
vina ${ }^{46}$. El turco le parecerá así a Lutero como la "vara de Dios" y el "servidor del diablo", es decir, por una parte un castigo divino y, por otra, una tentación de Lucifer ${ }^{47}$. Sin embargo, la solución de una cruzada, programada por la Iglesia de Roma, iba a ser rechazada por el mandato de Cristo de no oponerse al mal con el mal ${ }^{48}$. Lutero, más bien, reiteraba que la lucha, contra los propios vicios y pecados, debía ser interior. Esa lucha solo podía ser vencida con la penitencia y la oración, en la esperanza de la misericordia divina ${ }^{49}$. Cuando, después, los otomanos en 1529 amenazaron tomar Viena, Lutero llegará a identificar en ellos al enemigo escatológico, según la exégesis del pasaje bíblico de Daniel, 7, 2550. En razón de esta interpretación suya, el turco -ira del diablo contra el cristianismo- se convertirá para él en enemigo de los cristianos hasta el fin del mundo ${ }^{51}$. Lo cual llevará a Lutero a admitir, en su última obra importante sobre el tema, Vermahnung zum Gebet wider den Türken ${ }^{52}$, escrita al mismo tiempo que la toma de Buda por parte de Solimán el Magnífico en agosto de 1541, la posibilidad de una guerra dirigida por los príncipes. Aquí, además de la lucha espiritual por un arrepentimiento y una conversión radical, se revela, contra el peligro turco, el recurso a la guerra armada, la cual puede, sin embargo, decirse dichosa, así como los cristianos que mueren en ella, no persiguiendo ni gloria ni honor ni mucho menos riquezas ${ }^{53}$.

Las reflexiones de Lutero sobre la cuestión bélica mueven por una concepción religiosa, más bien que política ${ }^{54}$. En última instancia, la amenaza turca es para él una consecuencia del vicio y de la falta de arrepentimiento de los cristianos; el peligro que los turcos representan es, por tanto, definido en un sentido estrictamente espiritual.

46. Buzzi advierte que estas afirmaciones, cuyo sentido era más bien el de poner en claro las condiciones pecaminosas de la cristiandad para inducirla al arrepentimiento, estuvieron interpretadas literalmente, como se significaran por parte de Lutero la voluntad de no oponerse en absoluto al avance de los turcos (ver Buzzi, 2005, p. 26). Según Buzzi, también cuando Lutero se mostrará crítico en relación con el Edicto de Nuremberg emitido por Carlos $\vee$ en 1524, que declaraba necesaria la campaña militar contra los turcos, en realidad «non intendeva opporsi in assoluto alla necessità di difendersi dal pericolo Turco, quanto piuttosto criticare la presunzione dell'Imperatore di presentarsi come il defensor fidei, il difensore della fede e dei diritti di Dio» (Buzzi, 2005, pp. 26-27). Ver también Buzzi, 2017, pp. 111-119. Y además, Kritzl, 2008, pp. 21-47.

47. Ver Luther, Vom Kriege wider die Türken, WA, 30, II, p. 116. Con este escrito, terminado a finales de 1528 , y publicado a principio de 1529, Lutero quiere aclarar su postura contra algunas tesis que se le atribuyen, como que a los cristianos les está prohibido el servicio militar, o que se deba desear vivir bajo el dominio de los turcos. Ver Luther, Vom Kriege wider die Türken, WA, 30, II, p. 107.

48. Ver Luther, Vom Kriege wider die Türken, WA, 30, II, pp. 110 y 111. Ver Buzzi, 2005, p. 28.

49. Ver Luther, Vom Kriege wider die Türken, WA, 30, II, pp. 116 y 119. De hecho, el Emperador debe intervenir contra los turcos únicamente en nombre de la autoridad seglar que Dios le concedió como protección de los súbditos, pero no puede presentarse como el protector de la Iglesia. Ver Luther, Vom Kriege wider die Türken, WA, 30, II, p. 129. Y también Buzzi, 2005, p. 28.

50. Ver Carta de Lutero a Venceslao Link de 28 de octubre de 1529, WA Br 5, pp. 169-170.

51. Ver Carta de Lutero a Niccolò Hausmann de 26 de octubre de 1529, WA Br 5, pp. 166-167.

52. Ver Luther, Vermahnung zum Gebet wider den Türken, WA 51, pp. 577-625.

53. Ver Luther, Vermahnung zum Gebet wider den Türken, WA 51, p. 620

54. Ver Buzzi, 2005, pp. 25-26. 
Respecto a esta interpretación, Vitoria orientará su reflexión sobre la guerra hacia la realización de un orden de justicia natural, subrayando que la guerra puede ser lícita únicamente si es necesaria para restablecer la paz ${ }^{55}$. Al hacerlo, Vitoria se alejará no solo de Lutero, sino también del mismo Tomás de Aquino, que había abordado el tema de la guerra dentro del tratado sobre la virtud teologal de la caridad, como vicio contrario a esta última ${ }^{56}$. Por tanto, la discusión sobre la guerra con Vitoria desliza, aunque casi de modo inadvertido, de un plan estrictamente teologal, es decir, sobrenatural, al de una virtud cardinal, la justicia y, por tanto, natural.

Y así, una vez más, se constata por parte de Lutero y de Vitoria una preocupación compartida sobre un problema grave que afligía a la época de ambos, y aunque también Vitoria - como Lutero- reserva a los turcos el apelativo de perpetui hostes, se puede reconocer, al mismo tiempo, una distancia entre los dos ${ }^{57}$. Para Vitoria el fin de la guerra es la «pax et securitas reipublicae» 58 , bien indispensable al hombre y a la misma sociedad, porque, como él afirma, «nec summa etiam bona faciunt statum felicem sine securitate» ${ }^{59}$. La guerra es, pues, aceptada por el Maestro dominico únicamente come extrema ratio contra los que perturban la tranquilidad de la comunidad política y, con ello, la misma felicidad del hombre ${ }^{60}$. Por consiguiente, la única causa que se admite para una guerra es la reparación de las ofensas recibidas ${ }^{61}$ con la advertencia, sin embargo, de que no todas las ofensas son motivo suficiente para la guerra; en efecto, recuerda Vitoria, el tipo de pena debe ser conforme a la medida del delito ${ }^{62}$. La pena, de hecho, no debe exceder la grandeza de la ofensa, sino que debe mantenerse en los límites establecidos por la misma justicia63. De este modo, según Vitoria, es el derecho natural el que prescribe todo lo que es necesario para la conservación de la misma comunidad universal, porque, «quae necessaria sunt ad gubernationem et conservationem orbis, sunt de iure naturali» ${ }^{64}$. No en vano Vitoria vincula a esto el mismo ius gentium, precisa-

55. La guerra pertenece al derecho natural, y como sostiene santo Tomás, la ley evangélica no puede ir contra lo que es lícito por derecho natural; en efecto, es por un derecho natural por lo que es lícito rechazar la violencia con la violencia: «vim vi repellere licet» (Vitoria, Relecciones jurídicas y teológicas, vol. II, p. 766)

56. Ver Tomás de Aquino, Summa Theologiae, II-Ilae, q. 40.

57. Ver Vitoria, Relecciones jurídicas y teológicas, pp. 822-825. Aunque Vitoria tenía una visión universal, fundada sobre la natural cognatio del género humano, en su tratado sobre la guerra justa admite distinciones respecto al tratamiento en la guerra de los enemigos, in primis entre los cristianos y sus perpetui hostes, o sea, los turcos. Ver Galli, 2005, p. XLV.

58. Vitoria, Relecciones jurídicas y teológicas, vol. II, p. 768 y ver p. 790.

59. Ver Vitoria Relecciones jurídicas y teológicas, vol. II, p. 790.

60. Ver Vitoria, Relecciones jurídicas y teológicas, vol. II, p. 768

61. Para Vitoria, «una sola est causa iusti belli, scilicet, iniuria accepta» (Relecciones jurídicas y teológicas, vol. II, p. 786).

62. Ver Vitoria, Relecciones jurídicas y teológicas, vol. II, p. 832.

63. Ver Vitoria, Relecciones jurídicas y teológicas, vol. II, p. 772. Vitoria, admitiendo un único motivo de guerra justa, limitara drásticamente la posibilidad de guerra; sin embargo, la interpretación de la vindicta iniuriae acceptae puede ser muy amplia y puede llegar a permitir incluso el exterminio de los enemigos. Ver Vitoria, Relecciones jurídicas y teológicas, vol. II, p. 792. Ver Tosi, 2003, p. 79.

64. Vitoria, Relecciones jurídicas y teológicas, vol. II, p. 792. 
mente como garantía de una mayor objetividad y justicia para todos los pueblos del orbe ${ }^{65}$. El mundo, de hecho, no subsistiría si alguien no tuviese la fuerza y la autoridad de amenazar a los malvados para que no causaran daño a los buenos ${ }^{66}$.

\section{EN TORNO AL DOMINIUM}

Los puntos que sintéticamente hemos recordado hasta aquí, como posibles respuestas a Lutero por parte de Vitoria ${ }^{67}$, recuerdan a su vez una serie de cuestiones que implican ideas y conceptos que serán centrales para el debate filosóficoteológico suscitado por la Reforma.

A partir de los temas de la naturalis ratio y de la lex se pondrá la atención sobre el importante tema del dominium, entendido como facultas o potestas, elaborando de este modo una nueva definición ligada a las capacidades racionales del hombre y no a su estado de gracia o de pecado ${ }^{68}$. El dominium se configurará así como un derecho fundado en la imagen divina impresa en el hombre ${ }^{69}$. De este concepto, que será objeto de interés no solo de Vitoria, sino también de todos los autores de la segunda escolástica, la modernidad heredará un fundamento seguro para la afirmación de los derechos subjetivos inalienables ${ }^{70}$ y propios de todos los hombres, in primis el derecho a la libertad71.

El hombre, creado por Dios a su imagen está orientado, a pesar del pecado, hacia su Creador; Vitoria insiste, a diferencia de Lutero ${ }^{72}$, en el hecho de que el

65. Ver Vitoria, Relecciones jurídicas y teológicas, p. 666. Ver también Ramírez, 1955, p. 145; Pizzorni, 1988, p. 575.

66. Ver Vitoria, Relecciones jurídicas y teológicas, vol. II, pp. 768, 776 y 793.

67. Vitoria hace una referencia directa a Lutero, aunque no cita nunca sus obras textualmente. Recordemos que la bula papal Exsurge Domine prohibía a los cristianos leer, editar, publicar, poseer los escritos de Lutero. Ver «Exsurge Domine», en Denzinger, 1996, pp. 628-634.

68. Para Vitoria, a pesar del fomes peccati, la synderesis, «qui semper murmurat contra malum et mutat rationem ad bonum» (Vitoria, Incipiunt commentaria doctissimi Magistri fratris Francisci de Vitoria in primam partem s. Thome de Aquino, q. 79, a. 12, Archivo Histórico Dominicano de la Provincia España, ms. 2, Salamanca, fols. 199v-200v), puede aprender los primeros principios de la lex naturalis mostrándolos discursivamante por medio de la ratio.

69. El hombre, precisamente, por ser capax Dei es, para Vitoria, capax dominii. Ver Langella, 2015, p. 159. 70. Ver Tierney, 1997.

71. Según Annabel Brett, los maestros de la Segunda Escolástica se basan en dos nociones de derecho subjetivo: la primera equipara el derecho al dominium y a la libertad; la segunda, al contrario, liga el derecho a la naturaleza en cuanto justificaba las acciones como el resultado de una inclinación natural al propio bien. Ver Brett, 1997, PP. 138 Y 124.

72. Para Lutero, el pecado original es ciertamente la caída de la naturaleza humana y del oscurecimiento del entendimiento, de modo que también la voluntad es depravada y tiende necesariamente a la concupiscencia: «Sophistae cum de peccato originis loquuntur, tantum de misera et focola libídine seu concupiscentia loquuntur. Sed peccatum originale est vere totus lapsus naturae humanae, quod est intellectus obscuratus ut non agnoscamus amplius Deus et voluntatem eius, ut non animadventamus opera Dei; Deinde quod etiam voluntas mire est depravata, ut non fidamus misericordiae Dei, ut non metuamus Deus, sed securi, omisso verbo et voluntate Dei, sequimur concupiscentiam et ímpetus carnis. Item, quod conscientia» (Luther, Genesisforlesung, WA, 42, p. 86). 
ser humano, con motivo de su origen, no tiene una natural inclinación al mal73, en cuanto refleja en su misma naturaleza la imagen divina marcada por las potentiae rationales ${ }^{74}$. Vitoria entiende la razón como norma decisiva del obrar humano, y la libertad de cada uno se configura como postura esencialmente dominativa, pues, el sujeto libre está caracterizado ante todo por el dominio sobre sí y sus propios actos $^{75}$. Ahora bien, tener una postura dominativa equivale a una postura de libertad, porque es considerada que es la misma cosa para nuestros actos tener dominio sobre ellos y ser libres ${ }^{76}$. De este modo, también aquí, de un espacio estrictamente teológico, el de la disputa sobre el libre arbitrio suscitada por las posturas sobre la gracia de Lutero $^{77}$, se desliza lenta pero inexorablemente en un contexto filosóficojurídico de discusión. La capacidad deliberativa, propia del sujeto racional, se configurará en Vitoria, ante todo, como facultas o potestas dominativa ${ }^{78}$. En efecto, con Vitoria se asiste al aprovechamiento de la capacidad del hombre de contribuir al desarrollo de sí y de la sociedad, con una ampliación de los confines de la autonomía humana ${ }^{79}$. En la economía de la salvación el hombre no se configura como pasivo y objeto predestinado de la gracia divina, sino que se le atribuye un papel activo y dinámico ${ }^{80}$.

Así pues, Vitoria dará lugar a un cambio importante de perspectiva que implicará la afirmación de un modelo político que definitivamente superará el agustiniano, para el cual los vínculos de sujeción están destinados a contrarrestar únicamente la fuerza de la libido dominandi, que precisamente caracteriza la natura lapsa ${ }^{81}$.

73. Ver Vitoria, Relecciones jurídicas y teológicas, vol. II, pp. 220-225 y también pp. 232-235.

74. Ver Vismara, 2004, p. 26

75. Ver Grossi, 1973, pp. 134-135.

76. Ver Grossi, 1973, p. 148.

77. Para Lutero la fe es perfectamente suficiente para el cristiano, el cual no necesita obras para ser justificado. Negar obras meritorias desemboca necesariamente en la justificación por sola fide. Por otra parte, desde el momento en que solo la gracia puede salvar, no puede ni siquiera ejercerse el libre arbitrio. Ver Luther, Tractatus de libertate Christiana, WA, 7, pp. 53 y 61

78. En el prólogo de su comentario a la I-II de la Summa, Vitoria destacaba cómo Tomás, en ese lugar, trataba precisamente del hombre por estar hecho a imagen y semejanza de Dios dejando claro: «Imago consistit in hoc quod est habere placitum et dominium suorum actuum per libertatem» (Langella, 2013, Apéndice II, pp. 126-127). E inmediatamente después añadía: «est dominus [...] nihil aliud nisi quod habet eas in sua potestate et utitur eis si vult, et non si non vult». En efecto, para Vitoria, es dominus solo quien tiene la propiedad de la cosa en plenitud. El dominio, en sentido propio, lleva consigo necesariamente el carácter de independencia; se trata, pues, de una potestas -o derecho- que no está subordinado, aunque pueda ser limitado, pero siempre y solo accidentalmente, en su ejercicio, o, como afirma Domingo de Soto en su relectio De dominio, es la potestad o el derecho de poseer algo por cualquier uso que no esté prohibido por las leyes: «Dominium est potestas seu ius proprium assumendi rem ad quemcumque usum qui non est prohibitus lege» (Domingo de Soto, De dominio, en Relecciones y opúsculos, vol. I, p. 110).

79. Ver Vismara, 2004, p. 26

80. Ver Vismara, 2004, p. 26

81. Agustín afirma que Dios quiere que el ser racional, creado a su imagen, fuese señor únicamente de los seres irracionales y no de los propios semejantes. Ver san Agustín, De civitate Dei, XIX, 15 (PL XLI, 643-644). La armonía propia del estado de justicia preveía solamente la subordinación al hombre de los seres irracionales (Ferreiro, 2011, p. 34). Pero con el pecado original esa armonía se vino a menos: la propiedad privada, la esclavitud y el gobierno son formas de coacción impuestas por la condición 
Los vínculos de dominio ya no serán, de hecho, vistos como consecuencia del pecado original y el dominio asumirá un nuevo significado político. Vitoria afirmará, al mismo tiempo, tanto el ser sociable como la política de la naturaleza humana permitiendo, de este modo, a este último elemento constitutivo del hombre ser rescatado de una visión pesimista, que lo reconocía solamente como consecuencia de una culpa, sosteniendo, en cambio, la autonomía y legitimación del orden político y de sus vínculos a pesar de la visión luterana, para la que la necesidad del poder temporal reside por último en las irreparables consecuencias del pecado original ${ }^{82}$.

La idea renovada de dominium del hombre sobre sí y sobre realidades se convertirá así a partir de Francisco de Vitoria en la piedra angular de la cultura filosófico-política y jurídica de la edad moderna, porque lo que caracterizará al hombre de ahora en adelante será su capacidad deliberativa, su libertad. En otros terminos: «habere placitum et dominium suorum actuum per libertatem» 83 .

\section{BiBLIOgRAFÍA}

Agustín, san, De civitate Dei, en Patrologiae cursus completus... Series latina in qua prodeunt Patres, doctores scriptoresque Ecclesiae latinae a Tertuliano ad Innocentium III, ed. Jacques-Paul Migne, Parisiis, Apud Garnier Fratres, 18411969, vol. XLI, pp. 13-804.

Andreatta, Eugenio, Lutero e Aristotele, Padova, CUSL Nuova Vita, 1996.

Brett, Annabel S., Liberty, Right and Nature. Individual Rights in Later Scholastic Thought, Cambridge, Cambridge University Press, 1997.

presente del hombre incapaz de vivir de acuerdo con los imperativos de la razón. En otros términos, son medios para contener la inclinación del hombre al mal, consecuencia del pecado original. En efecto, para Agustín, la condición servil fue impuesta al hombre como motivo de su caída. Por eso la culpa, y no la naturaleza, mereció ese dominio despótico: «Proinde nusquam Scripturarum legimus "servum", antequam hoc vocabulo Noe iustus peccatum filii vindicaret. Nomen itaque istud culpa meruit, non natura» (san Agustín, De civitate Dei, XIX, 15, PL XLI, 643-644). Todas estas formas de coacción fueron impuestas a la presente condición del hombre por ser incapaz de vivir de acuerdo con los imperativos de la razón; y estas son simples medios para contener la inclinación del hombre al mal. En otros términos, el deseo del hombre de dominar a los otros hombres es un aspecto de la libido dominandi que precisamente caracteriza la natura lapsa (Ferreiro, 2011, p. 35). Y aunque al poder político también se le pueda entender como un remedio a la naturaleza caída (remedium peccati), en cuanto los vínculos de subordinación intentan conservar y recuperar un orden perdido, poniendo un freno a la inclinación viciosa del hombre, sin embargo, según Agustín, los vínculos de subordinación, con los que se identifica la política, no son parte de la naturaleza humana tal como fue creada ab origine.

82. No en vano, según Lutero, la función política y civil de la ley es proteger el mundo contra las consecuencias destructivas del pecado (ver Luther, Disputatio contra scholasticam theologiam, WA, 1, p. 227; y también López Hernández, 1981, p. 71). En otras palabras, para Lutero, las leyes son un mal que se tolera. «Para los escolásticos españoles, en cambio, la ley es un bien, un instrumento de educación en la virtud, complemento de la religión y herramienta necesaria para conseguir la felicidad política» (Contreras Aguirre, 2018, p. 160).

83. Langella, 2013, Apéndice II, pp. 126-127. 
Buzzi, Franco, «Guerra e pace in Martin Luther. Storia ed Evangelo», en Guerra e pace nel pensiero del Rinascimento, ed. Luisa Secchi Tarugi, Firenze, Franco Cesati Editore, 2005, pp. 23-46.

Buzzi, Franco, Erasmo e Lutero, Milano, Jaca Book, 2017.

Contreras Aguirre, Sebastián, «Lutero en Salamanca. Crítica de los escolásticos salmantinos a la teoría luterana de la ley», en Humanismo cristiano y Reforma protestante (1517-2017), ed. Miguel Anxo Pena González e Inmaculada Delgado Jara, Salamanca, Universidad Pontificia de Salamanca, 2018, pp. 159-173.

Denzinger, Heinrich, Enchiridion Symbolorum, definitionum et declarationum de rebus fidei et morum, ed. Peter Hünermann, Bologna, EDB,1996.

Ferreiro, Jazmín, «Acerca de la existencia de vínculos de dominio in statu innocentiae. La propuesta tomista frente a la formulación agustiniana», Scripta, 2 , 2011, pp. 31-44.

Galli, Carlo, «Introduzione», en Francisco de Vitoria, De iure belli, Roma Bari, Laterza, 2005, pp. V-LIX.

Gerson, Ioannes, Liber de vita spirituali animae, en Opera omnia, Antuerpiae, E. Du Pin, 1706, vol. III, pp. 1-72.

Grossi, Paolo, «La proprietà nel sistema privatistico della Seconda Scolastica», en La Seconda Scolastica nella formazione del diritto privato moderno, ed. Paolo Grossi, Milano, Giuffré, 1973, pp. 117-222.

Hernández Martín, Ramón, Francisco de Vitoria: vida y pensamiento internacionalista, Madrid, BAC, 1995.

Juan de Jesús María, «Francisco de Vitoria, conciliarista?», en Ephemerides carmeliticae, 1, 1947, pp. 103-148.

Kritzl, Johannes, Adversus turcas et turcarum Deum. Beurteilungskriterien des Türkenkriegs und des Islam in den Werken Martin Luthers, Bonn, Kultur und Wissenschaft, 2008.

Langella, Simona, «Le fonti teologiche della dottrina de bello in Francisco de Vitoria tra medioevo e età moderna. Nuove letture filologiche e teologico-giuridiche», en Guerra e Diritto. Il problema della guerra nell'esperienza giuridica occidentale tra medioevo e età contemporanea, ed. Aldo Andrea Cassi, Soveria Mannelli, Rubbettino, 2009, pp. 25-37.

Langella, Simona, Teología y ley natural. Estudio sobre las lecciones de Francisco de Vitoria, Madrid BAC, 2011.

Langella, Simona, La ciencia teológica de Francisco de Vitoria y la «Summa theologiae» de Santo Tomás de Aquino en el siglo XVI a la luz de textos inéditos, Salamanca, SEE, 2013.

Langella, Simona, «Francisco de Vitoria e il concetto di dominium», Ephemerides iuris canonici, 55, 2015, pp. 151-174. 
Langella, Simona, «Introducción», en Relecciones jurídicas y teológicas, edición crítica dirigida por Antonio Osuna Fernández-Largo, con la colaboración de Jesús Cordero Pando, Mauro Mantovani, Ramón Hernández Martín, Simona Langella y Ángel Martínez Casado, Salamanca, SEE, 2017a, vol. I, pp. 729-736.

Langella, Simona, «The Sovereignty of Law in the Work of Francisco de Vitoria», en At the Origins of Modernity. Francisco de Vitoria and the Discovery of International Law, ed. José Maria Beneyto y Justo Valera, Cham, Springer, 2017b, pp. 45-61.

Langella, Simona, «Vitoria y la teología como ciencia: una respuesta a Lutero», Azafea, 20, 2018, pp. 37-53.

León, fray Luis de, De legibus, ed. José Barrientos García, El Escorial/Madrid, Ediciones Escurialenses, 2005.

López Hernández, Carlos, Ley, Evangelio y Derecho Canónico en Francisco de Vitoria, Salamanca, Universidad Pontificia, 1981.

Luther, Martin, Werke. Kritische Gesamtausgabe, Weimar, Hermann Böhlaus, 1888-.

Mondin, Battista, Storia della teologia. Epoca Moderna, Bologna, Edizioni Studio Domenicano, 2002, vol. III.

Pizzorni, Reginaldo, «Lo ius gentium nel pensiero del Vitoria», in I diritti dell'uomo e la pace nel pensiero di Francisco de Vitoria e Bartolomé de las Casas, Milano, Massimo, 1988, pp. 569-583.

Quinto, Riccardo, Scholastica. Storia di un concetto, Padova, II Poligrafo, 2011.

Ramírez, Santiago, El derecho de gentes. Examen crítico de la filosofía del derecho de gentes desde Aristóteles hasta Francisco Suárez, Madrid/Buenos Aires, Ediciones Studium, 1955

Ramis Barcelò, Rafael, «La presencia de Erasmo en las obras de Vitoria y Soto», Relectiones, 5, 2018, pp. 93-114.

Soto, Domingo de, O. P., De dominio, en Domingo de Soto, O. P., Relecciones y opúsculos, ed. Jaime Brufau Prats, Salamanca, Editorial San Esteban, 1995, vol. 1, pp. 98-192.

Suárez, Francisco, Opera omnia, tomo XII, ed. Ludovicum Vivès, París, Bibliopolam, 1857.

Urdánoz, Teófilo, «Introducción», en Francisco de Vitoria, Obras de Francisco de Vitoria: Relecciones Teológicas, ed. Teófilo Urdánoz, Madrid, Ed. Católica BAC, 1960, pp. 410-429.

Tierney, Brian, The Idea of Natural Rights. Studies on Natural Rights. Natural Law and Church Law, 1750-1625, Atlanta (Georgia), Scholars Press for Emory University, 1997. 
Tosi, Giuseppe, «La teoria della guerra giusta in Francisco de Vitoria», en Figure deIla guerra. La riflessione sulla pace, conflitto e giustizia tra Medioevo e prima età moderna, ed. Merio Scattola, Milano, FrancoAngeli, 2003, pp. 63-87.

Vismara, Paola, Oltre I'usura. La Chiesa moderna e il prestito a interesse, Soveria Mannelli, Rubbettino, 2004.

Vitoria, Francisco de, O. P., Comentarios a la Secunda secundae, ed. Vicente Beltrán de Heredia, Salamanca, Biblioteca de Teólogos Españoles, 1932, vol. I.

Vitoria, Francisco de, O. P., De legibus, introducción Simona Langella, transcripción y notas José Barrientos García y Simona Langella, traducción al español Pablo García Castillo y traducción al italiano Simona Langella, Salamanca, Ediciones Universidad de Salamanca, 2010.

Vitoria, Francisco de, O. P., Incipiunt commentaria doctissimi Magistri fratris Francisci de Vitoria in primam partem s. Thome de Aquino, ms. 2, Salamanca, Archivo Histórico Dominicano de la Provincia España.

Vitoria, Francisco de, O. P., Relecciones jurídicas y teológicas, ed. crítica dirigida por Antonio Osuna Fernández-Largo, con la colaboración de Jesús Cordero Pando, Mauro Mantovani, Ramón Hernández Martín, Simona Langella y Ángel Martínez Casado, Salamanca, SEE, 2017, 2 vols. 